UDC: $811.134 .1^{\prime} 271.2$

DOI: https://doi.org/10.18485/beoiber.2018.2.1.16

\author{
Neda Pons' \\ Doctoranda en la Universidad de Belgrado \\ Serbia
}

\title{
LA IDEOLOGÍA DEL PURISMO LINGÜÍSTICO EN LA COMUNIDAD VIRTUAL LADINOKOMUNITA
}

\begin{abstract}
Resumen
En este artículo examinamos la ideología del purismo lingüístico entre los miembros de la comunidad virtual Ladinokomunita, que fue fundada en 2000 con el objetivo de promover el uso de la lengua judeoespañola y la cultura sefardí. En la investigación partimos de la idea de que la ideología como parte integral de la identidad social es algo que se construye y transforma en la interacción lingüística mediante el uso de las tácticas de intersubjetividad (Bucholtz y Hall 2004, 2005) y siempre en función de un contexto social más amplio. Por lo tanto, teniendo en cuenta las tendencias de glocalización que operan en la sociedad contemporánea, en este trabajo analizamos las actitudes puristas presentes en Ladinokomunita desde el punto de vista del enfoque de tratamiento social (ing. societal treatment approach) (Garrett et al. 2003) con el objetivo de mostrar que la ideología del purismo lingüístico de sus miembros es una manifestación de procesos sociales más amplios, en los que se intenta reconstruir y revitalizar la identidad étnica de la comunidad sefardí.

Palabras clave: purismo lingüístico, identidad étnica, tácticas de intersubjetividad, judíos sefardíes, lengua judeoespañola.
\end{abstract}

\section{THE IDEOLOGY OF LINGUISTIC PURISM IN THE LADINOKOMUNITA VIRTUAL COMMUNITY}

\begin{abstract}
In this article we examine the ideology of linguistic purism among the members of the Ladinokomunita virtual community, which was founded in 2000 with the aim of promoting the use of the Judeo-Spanish language and Sephardic culture. In the research we start from the idea that ideology as an integral part of social identity is something that is constructed and transformed in linguistic interaction through the use of tactics of intersubjectivity (Bucholtz and Hall 2004, 2005) and always in the function of a broader social context. Therefore, taking into account the tendencies of glocalization that operate in contemporary society, in this work we analyze the purist attitudes present in Ladinokomunita from the point of view of the social treatment approach (Garrett et al. 2003) with the aim of showing that the

1 nedapons@gmail.com
\end{abstract}


ideology of the linguistic purism of its members is a manifestation of broader social processes, in which attempts are made to reconstruct and revitalize the ethnic identity of the Sephardic community. Spanish.

Key words: linguistic purism, ethnic identity, tactics of intersubjectivity, Sephardic Jews, Judeo-

\section{Introducción}

En este trabajo analizamos la ideología del purismo lingüístico presente en las actitudes de los miembros de la comunidad virtual Ladinokomunita. Esta comunidad fue fundada en 2000 por Rachel Amado Bortnick con el objetivo de revitalizar la lengua y la cultura judeoespañolas, tanto a través de la promoción de la interacción en esta lengua como a través de las discusiones sobre diferentes temas lingüisticos, culturales e históricos de la comunidad sefardí. Según sus palabras, la fundación de este grupo fue inspirada por las ideas y conclusiones de una conferencia sobre las cuestión de ortografía judeoespañola que fue celebrada en Jerusalén en 1999 (Amado Bortnick 2004: 3).

La lengua judeoespañola, desde su formación hasta la actualidad, tanto en términos de número de hablantes, como en términos de su estatus social, siempre ha pertenecido al grupo de lenguas minoritarias ${ }^{2}$. Esto significa que los judíos sefardíes, desde su expulsión de la Península lbérica hasta hoy, han formado una comunidad minoritaria con su propia lengua étnica y "[...] han vivido en un territorio donde se habla una lengua distinta que pertenece a una comunidad mayoritaria social, política y económicamente más poderosa, que es organizada en una entidad política llamada el estado" 3 (Vučina Simović y Filipović 2009: 33).

De acuerdo con la definición constructivista de la identidad étnica (Dženkins 2001: 93-99), podemos decir que la identidad etnolingüística de la comunidad sefardí se ha desarrollado como resultado de un proceso dialéctico de definiciones internas y externas. Bajo "la definición interna" comprendemos la autoconciencia de la propia naturaleza en relación con los demás, que se deriva de un repertorio común de significados y prácticas culturales, mientras que bajo "la definición externa" nos referimos a la caracterización y categorización por aquellos "del otro lado de la frontera étnica". Es importante señalar que esta categorización afecta dicha autoidentificación en forma de su confirmación o su negación. En este sentido, en el curso de la historia, el papel de la lengua judeoespañola en la construcción de la identidad étnica sefardí en gran medida ha sido determinado por la categorización "desde fuera", o sea, por un contexto más amplio en el que se desarrollaba la interacción social entre los sefardíes y los grupos etnolingüísticos

2 Aunque los conceptos "la lengua minoritaria" y "el grupo minoritario" aparecen por primera vez en el contexto de la formación de los Estados nacionales a finales del siglo XVIII, aquí son utilizados en un sentido más general de minoría numérica.

3 "[Manjinske grupe] žive na teritoriji gde se govori neki drugi jezik društveno, politički i ekonomski moćnije većinske zajednice koja je organizovana u politički entitet koji nazivamo državom." 
mayoritarios (más detalles en Nedović Pons 2016).

Un ejemplo de lo dicho se puede encontrar en la formación de estados nacionales en los territorios otomanos en el siglo $\mathrm{XIX}$ y a principios del siglo $\mathrm{XX}$, cuando se produjo un cambio significativo en las relaciones sociales entre diferentes grupos étnicos. En el ambiente en el que, como idioma oficial y factor homogeneizador de la nación emergente, las autoridades promovían el idioma del grupo étnico dominante, la lengua de los sefardíes era categorizada como una lengua minoritaria, es decir, de menor prestigio social, lo que llevó a su deslegitimación en la vida pública del estado. Como muestran varios estudios (ver, por ejemplo, Vučina Simović 2016, Vučina Simović y Filipović 2009, Seloni y Sarfati 2013), la ideología prevaleciente del monolingüismo nacional tuvo profundas consecuencias para la definición interna de la identidad etnolingüística de las comunidades sefardíes, que empezaron a abandonar su lengua étnica en beneficio de las lenguas estándar de los estados nacionales en los que vivían, manteniendo al mismo tiempo su distintividad étnica. ${ }^{4}$

De la misma manera, podemos decir que, hoy en día, en la sociedad postmoderna, la definición interna de la identidad etnolingüística sefardí está altamente influenciada "desde fuera", por "la valoración global de las identidades particulares" (Robertson 1992: 130). Esta tendencia a la localización global, también llamada "glocalización" (Robertson 1995), cuyos inicios se remontan a la segunda mitad del siglo XX, está basada en el flujo global de información e ideas sobre la cultura y los elementos culturales como valores universales, y puede ser definida como "[...] una expresión de fortalecimiento, revitalización o reinvención de las identidades culturales y tradiciones locales basada en elementos étnicos, sociales o religiosos "5 (Schurkens 2003: 217). En el plan del lenguaje, la glocalización se manifiesta a través del modelo postmodernista de estandardización lingüística (Geeraerts 2003), o sea, a través de "la valoración igual de todas las variedades lingüísticas (como valores culturales)" y la promoción del multilingüismo y plurilingüismo por parte de las principales organizaciones culturales a nivel internacional (Filipović 2009: 61). En este sentido, la aspiración creciente a la diferenciación lingüística entre diferentes grupos minoritarios, o sea, a la estandarización de sus respectivas variedades étnicas, en este caso de la lengua judeoespañola, representa un reflejo de la valorización positiva de la diversidad etnocultural a nivel mundial.

Según el Atlas UNESCO de las lenguas del mundo en peligro (Moseley 2010), el

4 Como señala Şaul (2013: 239-244), de acuerdo con la idea de que cada nación debe tener su propia lengua nacional, en la República de Turquía la lengua étnica de los sefardíes fue categorizada como lengua perteneciente a la nación española, mientras que como lengua materna de los judíos fue reconocido solamente el hebreo. En este clima de deslegitimación de su lengua hablada y la legitimación de su lengua sagrada que no podían hablar, los sefardíes no tuvieron más remedio que alejarse cada vez más del judeoespañol y desplazar esta lengua a favor del idioma turco.

5 "[...] an expression of fortification, revitalization or reinvention of local cultural identities and traditions based on ethnic, social, or religious elements." 
judeoespañol es clasificado como una lengua "seriamente en peligro" 6 , teniendo en cuenta varios factores, entre los cuales encontramos la transmisión intergeneracional de la lengua, el número absoluto de hablantes y la proporción de hablantes en el conjunto de la población (UNESCO 2003: 6-7). Sin embargo, dado que el judeoespañol no es el único idioma que utilizan sus hablantes (cuyo nivel de fluidez en esta lengua es cuestionable (Harris 2011: 58)), y que estos, además, viven dispersos en varios países del mundo (principalmente en Israel, los Estados Unidos y Turquía), es muy díficil determinar el número exacto de las personas que siguen utilizando la lengua sefardí en la actualidad. ${ }^{7}$ La dispersión geográfica, la falta de una comunidad etnolingüística en el sentido tradicional (es decir, físico) y la integración de los sefardíes en la sociedad secular, encaminan a los activistas de la revitalización lingüística hacia "los espacios sociales transnacionales" (Roudometof 2005: 120), en primer lugar hacia Internet, que, según Štulić y Rouissi (2017: 293-294), como una "sociedad global emergente", crea nuevas oportunidades para el uso y la transmisión del judeoespañol, así como para su documentación y revalorización positiva, tanto a nivel de la comunidad misma, como a nivel del contexto transnacional.

Por consiguiente, la actividad del grupo virtual Ladinokomunita en el campo de la revitalización de la lengua judeoespañola debe ser interpretada en el contexto de la mencionada revalorización de la diversidad etnocultural y etnolingüística en el ámbito transnacional, $y$ especialmente en el ámbito de Internet ${ }^{8}$. En el presente artículo, la ideología del purismo lingüístico entre los activistas de este grupo es analizada a través del prisma de su actitud hacia el judeoespañol como uno de los elementos fundamentales en la revitalización y reconstrucción de su etnicidad. La palabra "reconstrucción" apunta a la definición de la identidad étnica como una construcción dinámica y variable (Dženkins 2001: 26), que una determinada comunidad construye y transforma en la interacción social con otros grupos étnicos, que por su parte, como ya se ha indicado, frecuentemente desde una posición dominante categorizan positiva o negativamente las identidades étnicas minoritarias. Así podemos afirmar que el contenido cultural de la identidad dentro de la propia comunidad puede cambiar de acuerdo con los cambios en

${ }^{6}$ La escala de la vitalidad lingüistica va de 5 a 0 y comprende los siguientes niveles: a salvo (5), vulnerable (4), en peligro (3), seriamente en peligro (2), en situación crítica (1), extinta (0). Una lengua "seriamente en peligro" se define de la siguiente manera: "sólo los abuelos y las personas de las viejas generaciones hablan la lengua. Los miembros de la generación parental, si bien pueden comprenderla, no la hablan entre sí, ni tampoco con sus hijos" (Moseley 2010).

7 Por ejemplo, Harris (1999: 125) afirma que en 1998 había unos 20,000 hablantes, pero en un estudio más reciente estima que ya en 2009 este número fue reducido a unas 11,000 mil personas (Harris 2011: 58). Por otra parte, según el sitio web de Ethnologue (Simons y Fenning 2018), actualmente hay unos 137,000 hablantes, mientras que, basándose en la afirmación de Hetzer (2001: 144), el Atlas UNESCO de las lenguas del mundo en peligro presenta un número de 400,000 personas que todavía tienen un cierto dominio de esta lengua (Moseley 2010).

8 Para más detalles sobre diferentes aspectos tecnológicos y sociolingüísticos del uso del judeoespañol en Internet ver Štulić y Rouissi 2017.

BEOIBERÍSTICA Vol. II / Número 1 (2018) | 251-285 
las relaciones de poder en un contexto social e ideológico más amplio.

En lingüística sociocultural, estas relaciones son denominadas utácticas de intersubjetividad" (Bucholtz y Hall 2004, 2005). Este término enfatiza la importancia del rol de todos los agentes involucrados en la interacción social, que en diferentes contextos temporales y espaciales son guiados por diferentes ideologías y diferentes intereses sociales. Las relaciones intersubjetivas comprenden en primer lugar las tácticas de adecuación y distinción como construcción de la similitud o diferencia social, luego las tácticas de autorización y deslegitimación como asignación o denegación de la autoridad en el proceso de determinación de las fronteras identificativas, y finalmente las tácticas de autentificación y desnaturalización como determinación del significado de elementos "auténticos" e "inauténticos" de la identidad (Bucholtz y Hall 2005: 598-605).

Utilizando el aparato analítico de las mencionadas tácticas de intersubjetividad, en este trabajo intentamos mostrar que la ideología del purismo lingüístico dentro del grupo Ladinokomunita debe ser entendida como una manifestación de la realidad extralingüística de los miembros del grupo, es decir, como un reflejo de la reconstrucción de la identidad étnica sefardí, con referencia particular al contexto sociolingüístico e ideológico de la sociedad globalizada. En este sentido, comenzamos con una breve reseña de la historia del idioma judeoespañol, para seguir con una presentación más detallada del grupo Ladinokomunita y del marco metodológico de esta investigación. Finalmente, después de una breve revisión del concepto del purismo lingüístico y su relación con la ideología de la lengua estándar, presentamos los resultados del análisis de actitudes puristas entre los miembros de esta comunidad virtual.

\section{Los sefardies y su lengua9}

La palabra "Sefarad" es un topónimo hebreo que originalmente significaba "país occidental", pero que en el siglo VIII de nuestra era adquirió el significado del extremo occidental de Europa, o sea, la Península Ibérica (Díaz-Mas 2006 [1986]: 28). En este trabajo, bajo el término "sefardí" nos referimos a los descendientes de los judíos que vivieron en la Península lbérica desde la antigüedad hasta el siglo XV (Vidaković- Petrov 2001 [1986]: 7) y que, por un decreto real, en el año 1492 fueron expulsados de estas tierras ${ }^{10}$. Una parte de los judíos perseguidos se asentaron en una amplia área alrededor del Mediterráneo, incluyendo el sur de Francia, Italia, Países Bajos, Marruecos y otros países del norte de África bajo la influencia otomana, mientras que la mayoría se dirigió hacia el Imperio Otomano, que en aquel entonces incluía la actual Turquía, Grecia,

9 Partes del artículo publicado previamente en Nedović Pons 2016 han sido incluídos en esta sección.

10 Díaz-Mas (2006 [1986]: 28-29) explica que existe una acepción diferente de este término, según la cual el vocablo "sefardín significa todo lo "no asquenazí". 
Albania, Macedonia, Serbia, Bosnia y Herzegovina, Bulgaria, así como partes de Croacia, Rumania y Hungría (Zucker 2001: 4). La inestabilidad política y las guerras en esta región a finales del siglo XIX y en la primera mitad del siglo XX hicieron que la población sefardí emigrara una vez más, formando así la llamada "diáspora secundaria" (Díaz-Mas 2006 [1986]: 65) en los países de América del Norte y América del Sur, así como en algunos países de Europa occidental e Israel.

La lengua de los judíos sefardíes del Oriente ${ }^{11}$ es conocida bajo varios nombres populares: espanyol/spanyolit/spanyol, djudio/djudyo, djidio/djidyo, djudezmol judezmo, ladino etc., que reflejan diferentes posiciones ideológicas de sus hablantes (ver Bunis 2008, 2011a). En el campo de la lingüística, y especialmente a partir de la celebración del Primer Simposio de Estudios Sefardíes en 1964 en Madrid, para la lengua vernácula se utiliza generalmente el término "judeoespañol»12, lo que apunta a la naturaleza dual de la identidad étnica de los sefardíes. Con la palabra "judío" se marca su pertenencia a la nación judía en un sentido más amplio, mientras que la palabra "español» indica los siglos de su presencia en la Península lbérica. Por otra parte, el término "ladino", según el acuerdo de los participantes en el Simposio, queda reservado para la lengua de traducciones literales de los textos hebreos sagrados a las variedades romances (véase, por ejemplo, Séphiha 1998) ${ }^{13}$. Sin embargo, la cuestión del nombre de la lengua está lejos de ser un asunto resuelto: el glotónimo para la lengua étnica sefardí ha sido objeto de diversas controversias ideológicas, tanto entre los hablantes como en círculos acádemicos (más detalles en Şaul 2013). Hoy en día, somos testigos del uso sinonímico de los términos "el judeoespañol" y "el ladino", especialmente en Israel y los Estados Unidos. El mejor ejemplo del uso de la palabra "ladino" en el sentido de la lengua étnica de la comunidad sefardí es el propio nombre Ladinokomunita.

Puesto que después de la expulsión en 1492 la lengua de los sefardíes en el Imperio otomano ha quedado "[...] fuera de la competencia de la norma estándar española [...]", se puede decir que el judeoespañol “[...] constituye la única variedad diatópica que

${ }^{11}$ Los factores sociolingüísticos bien distintos dentro de la comunidad sefardí en el norte de África hicieron que el desarrollo de su variedad vernácula siguiera un curso peculiar, formando así una lengua llamada la haquitía, que dentro del campo de la lingüística se analiza en general como una variedad diferente.

12 Şaul (2013: 218) destaca que los sefardíes para su lengua en la interacción cotidiana nunca utilizaron el término “judeoespañol" y que esta palabra apareció por primera vez en la prensa sefardí en el último cuarto del siglo XIX.

${ }^{13}$ Esta propuesta se basa en el uso del término "ladino" dentro de la comunidad sefardí en la época posterior a la expulsión. Antes del año 1492, esta palabra se refería a la lengua romance hablada por los judíos (y no solo por los judíos) en la Península ibérica. Utilizando este término, los judíos marcaban la diferencia entre su lengua sagrada, el hebreo, y la variedad romance como una lengua "no judía", o sea, de origen latino (Bunis 2008: 419-420). Por otro lado, en los territorios otomanos ya en el siglo XVI, la palabra "ladino" empieza a utilizarse en el sentido de la lengua de traducciones de los textos sagrados, para llegar a significar, en los siglos XVIII y XIX, el lenguaje escrito (e impreso) de la literatura religiosa y didáctica de los sefardíes, y en consecuencia, el tipo de letra llamado rasí, que se utilizaba para imprimir estos textos (̧̧aul 2013: 185-195). 
quiebra la unidad fundamental del español" (Quintana 2010: 34). En realidad, esta lengua se formó como resultado del proceso de la koineización (Minervini 2006) y por lo tanto se puede definir como "[...] variedad suprarregional de base castellana, surgida por adaptación en el contacto entre hablantes de distintas lenguas y dialectos iberorrománicos [...]" (Minervini 2013: 324), que presenta también rasgos del hebreo, en forma de elementos léxicos relacionados con el dominio de tradición y religión (Bunis 2011b: 27), así como de las lenguas de adstrato según las regiones de asentamiento (turco, griego, serbio, búlgaro, etc.). Como destaca Minervini (2013: 324), es en el siglo XVIII, después de la fase formativa en los siglos XVI y XVII, cuando el judeoespañol "[...] aparece, al menos a nivel escrito, con su fisionomía propia, bien distinta de la del español peninsular". Dada la oleada de modernización y la educación en las lenguas de las culturas occidentales en el Imperio otomano, en el siglo XIX esta fisionomía cambiará bajo una notable influencia léxica (en ciertos aspectos también sintáctica) del francés y, en menor medida, el italiano y el alemán (Minervini 2013: 325). Por otra parte, según Bornes Varol (2017: 164), fue el contacto restablecido con el español peninsular ${ }^{14}$ que dejó unas huellas más profundas en el desarrollo del judeoespañol en ese período: "[...] el peso del español como norma de prestigio era mucho mayor porque era evidente para todas las personas y no solo para la élite occidentalizada." ${ }^{15}$ Este contacto, como afirma la misma autora, produjo una gran inseguridad entre los hablantes del judeoespañol, que empezaron a considerar su lengua como "un dialecto corrompido" de la lengua española. Por lo tanto, los escritores sefardíes intentaron rehispanizar su idioma de una manera bastante caótica, inventando nuevas formas lingüísticas, que fueron bien aceptadas por los sefardíes de esa época (Bornes Varol 2017: 183). Sin embargo, como es sabido, el proceso del desarrollo de la lengua judeoespañola será detenido debido la desintegracíon política del Imperio otomano, la dominación de la ideología monolingüe de los estados nación, la Segunda Guerra Mundial y otras circunstancias históricas, políticas y culturales de la edad contemporánea.

En otro lugar (Nedović Pons 2016) hemos mostrado que estos contactos lingüísticos la percepción del papel de la lengua judeoespañola en la (re)construcción de la identidad sefardí distintiva cambió durante la historia de acuerdo con los diferentes contextos sociales e ideológicas en los que vivía la comunidad sefardí, y que esta percepción siempre fue basada en diversas relaciones intersubjetivas con otras comunidades étnicas y nacionales. En este artículo analizamos el papel que la lengua judeoespañola juega en el proceso de la (re)construcción de la identidad etnolingüística de los sefardies en el contexto de la sociedad contemporánea, en la cual, como ya se ha destacado, las ideologías lingüísticas y las estructuras sociales a nivel supranacional (al

${ }^{14}$ Este contacto se produjo principalmente mediante la comunicación entre las élites intelectuales sefardíes y españolas.

15 "[...] the weight of Spanish as a norm of prestige was much bigger because it was evident for all the people and not only for a westernized elite." 
menos nominalmente) afirman la importancia del multilingüismo y el uso de variedades minoritarias, y en la cual las relaciones sociales están cada vez menos vinculadas a los límites territoriales (Grieg 2002: 229). Con esto nos referimos al análisis de la interacción lingüística dentro del grupo virtual Ladinokomunita, en el que los hablantes de esta lengua utilizando diferentes tácticas de intersubjetividad continúan negociando el significado del contenido cultural y lingüístico en la reconstrucción de su identidad étnica.

\section{Ladinokomunita Yahoo Group}

Según Rachel Amado Bortnick (2004: 3), la creadora y la administradora principal del grupo, "Ladinokomunita es la primera y la única lista de correspondencia en judeoespañol en Internet,"16. Aunque ya no es la única ${ }^{17}$, esta comunidad virtual es, sin duda alguna, pionera en los esfuerzos por preservar y revitalizar el idioma judeospañol y la cultura sefardí. Fue fundada en enero de 2000 con el objetivo de promover la herencia lingüística y cultural de los sefardíes, y hoy en día cuenta con 1619 miembros de diversas partes del mundo, por lo que puede considerarse, según Filipović (2015: 28), como un nuevo tipo de comunidad de práctica (en inglés community of practice). Basándose en la definición dada por Eckert y McConnell-Ginet (1992), la misma autora bajo el concepto de la comunidad de práctica entiende "[...] un grupo de individuos que trabajan juntos para alcanzar objetivos sociales comunes"18. Los "objetivos sociales comunes" del grupo Ladinokomunita son formulados de la siguiente manera en el mensaje de bienvenida, que se encuentra en la página principal. El propósito de Ladinokomunita es:

1. promover el uso de Ladino;

2. difundir el uso de un método estandarizado para escribir ladino en caracteres romanos, de acuerdo con las reglas establecidas por la revista "Aki Yerushalayim".

(http://www.akiyerushalayim.co.il/ay/075/075 05 grafya.htm);

3. promover el conocimiento de la historia y cultura sefardí. ${ }^{19}$ (https://groups.yahoo.com/neo/groups/Ladinokomunita/info)

Hablando de este grupo, Bunis (2016: 324) destaca que una de sus características principales es "[...] una atmósfera postmoderna de igualitarismo, en la que los expertos académicos de renombre mundial especializados en djudezmo y la literatura

16 "Ladinokomunita is the first and the only Judeo-Spanish correspondence list on the Internet."

17 Para ver una lista más amplia de las comunidades sefardíes en Internet consultar Romero 2017: 280.

18 "Delatna zajednica definiše se kao grupa pojedinaca koji zajedno delaju u cilju postizanja zajedničkih društvenih ciljeva."

19 "The purpose of the Ladinokomunita is to: 1. promote the use of Ladino; 2 . spread the use of a standardized method for spelling Ladino with Roman characters, according to the rules established by the journal "Aki Yerushalayim." (http://www.aki-yerushalayim.co.il/ay/075/075_05_grafya.htm); 3. promote knowledge of Sephardic History and culture." (https://groups.yahoo.com/neo/groups/Ladinokomunita/info) 
judeoespañola y los miembros ordinarios de la comunidad de habla y sus admiradores interactúan entre sí en lo que ambos lados ven como un sagrada misión." ${ }^{20}$

Nuestro análisis muestra que el mayor número de miembros de esta comunidad es bilingüe o multilingüe, que posee un alto nivel educativo y pertenece al grupo de edad de más de 70 años ${ }^{21}$. Por lo tanto, muchos de ellos "[...] se consideran a sí mismos miembros de las últimas generaciones que usan activamente el djudezmo, y sus mensajes a menudo son caracterizados por un sentido de urgencia: los últimos intentos de rescatar todo lo que pueden de esta lengua, una vez dinámica pero ahora en peligro de extinción"22 (Bunis 2016: 323-324). Sin embargo, es importante señalar que, aunque la mayoría de miembros son los sefardíes, mayoritariamente aquellos cuyos ancestros provienen de los territorios del Imperio Otomano (Amado Bortnik 2004: 10), en esta comunidad son bienvenidos tanto los miembros de otras ramas de la nación judía, como los no judíos.

Durante los 18 años de la existencia de esta lista de correspondencia ${ }^{23}$, la comunicación escrita de carácter asincrónico se desarrolló exclusivamente en el idioma judeoespañol y, hasta la fecha, han sido enviados más de 58,000 correos electrónicos, siempre sometidos a un proceso de corrección ortográfica y gramatical por los moderadores del grupo. El espacio virtual de esta comunidad sefardí está marcado por las discusiones sobre las cuestiones lingüísticas, culturales, históricas y otros temas del mundo sefardí, por medio de los cuales sus miembros desarrollan "un sentimiento de proximidad, identidad y solidaridad" (Filipović 2015: 27), siempre en búsqueda de un lugar propicio para su cultura en el contexto social más amplio. En ese sentido, ellos discuten y negocian el significado de ciertos componentes de su identidad étnica, en primer lugar de la lengua, confrontando diferentes puntos de vista y diferentes posiciones ideológicas a través del uso de las mencionadas tácticas de intersubjetividad ${ }^{24}$. Uno de los temas de estas discusiones es a menudo la cuestión de la "pureza" del idioma.

Hoy en día, los círculos académicos muestran un gran interés en diferentes aspectos del grupo Ladinokomunita. Por ejemplo, el papel de este espacio virtual en la reconstrucción de la identidad étnica sefardí fue analizado por Held (2010), Brink-Danan

20 "[...] a postmodern atmosphere of egalitarianism, in which academically world-renowned experts in Judezmo language and literature and rank-and-file members of the speech community and its admirers interact with one another in what both sides see as a sacred mission."

${ }^{21}$ Un cierto número de miembros que participaron activamente en el grupo y cuyas actitudes lingüísticas han sido analizadas en esta investigación, hoy, desafortunadamente, ya no están vivos.

22 "[...] consider themselves to be members of the last generations actively using Judezmo, and thus their messages are often characterized by a sense of urgency-last minutes attempts to rescue whatever they can of this once-dynamic but now-endangered Jewish tongue."

${ }^{23}$ Para una clasificación más detallada de las listas de correspondencia en Internet ver Crystal 2001: $11-12$.

${ }^{24}$ Se puede decir que estas polémicas siguen las huellas de la prensa sefardí moderna de finales del siglo XIX y la primera mitad del siglo XX (ver, por ejemplo, Bunis 1996 y Romero 2010). 
(2011) y Alten (2012), mientras que Bunis (2016: 324) lo analiza como cun foro para el discurso sobre el djudezmo". Otros autores (Pierson 2010; López Fernández 2015; Romero 2017) examinan el funcionamiento del foro dentro de un contexto más amplio del uso y la revitalización del judeoespañol en Internet. En algunos de estos trabajos este mundo virtual en el que se utiliza la lengua étnica de los sefardíes es llamado "tierra del djudezmo sin límites geográficos" (ing. "geographically border-free Judezmoland", Bunis 2016), "tierra del ladino" (ing. "Ladinoland", Brink-Danan 2011), "hogar digital" (ing. "digital homeland", Held 2010), o una tierra virtual en la que, después de una larga vida "en tierras ajenas" muchos miembros del grupo encuentran un nuevo hogar (Romero 2017: 288). Del mismo modo, en este estudio "la tierra virtual sefardí" llamada Ladinokomunita es presentada como el contexto en el que sus "habitantes" a través de la interacción social aplican y modifican las ideologías y los modelos culturales existentes (Filipović 2009: 115) en la reconstrucción de su identidad étnica.

\section{El marco metodológico}

Los resultados presentados en este trabajo forman parte de una investigación más amplia sobre el papel de la ideología de la cultura lingüistica estándar en la reconstrucción de la identidad etnolingüística sefardí en Internet, en la que el grupo Ladinokomunita fue analizado como un estudio de caso. Teniendo en cuenta la especificidad del contexto virtual en el que se desarrolla la comunicación de esta comunidad de prácticas, así como la distancia física de sus miembros, en este caso las ideologías y actitudes lingüisticas son examinadas desde la perspectiva del enfoque de tratamiento social (ing. societal treatment approach) (Garrett et al. 2003: 16). En la mayoría de los casos, este enfoque se basa, por una parte, en la observación y otros métodos de investigación etnográfica $y$, por otra parte, en el análisis de contenido cualitativo, con lo que «[...] a menudo profundiza en los antecedentes socioculturales y políticos de las actitudes [...],25 (Garrett 2007: 116).

Por lo tanto, con permiso explícito de la fundadora del sitio, Rachel Amado Bortnick, en el proceso de recopilación de datos utilizamos el método de observación de las actividades y los archivos del grupo Ladinokomunita, compuestos por más de 58000 correos electrónicos enviados en el período de enero de 2000 a diciembre de 2017. Con el objetivo de proporcionar la credibilidad y validez de los resultados, este procedimiento fue complementado con la técnica del cuestionario sociolingüístico, que a finales de diciembre de 2017 fue enviado a los miembros del grupo por correo electrónico, y al que respondieron 44 miembros activos de origen sefardí $(2.7 \%$ del número total de miembros).

\footnotetext{
25 "[...] often delve deeper into the sociocultural and political backdrop to attitudes [...]."
} 
Los datos recogidos de esta manera posteriormente fueron sometidos al análisis de contenido cualitativo, lo que implica una reducción cualitativa y "[...] descripción sistemática del significado de los datos cualitativos" ${ }^{26}$ (Schreier 2014: 170), o, en nuestro caso, un intento de identificar los significados clave (Patton 2001: 453) que los miembros del grupo Ladinokomunita atribuyen a la lengua judeoespañola en el proceso de la reconstrucción de su identidad étnica. En este sentido, nuestro análisis en gran medida está basado en los conceptos del análisis del discurso "etnográfico-sociolingüístico" (Blommaert 2005: 16), en el que, además de la observación de la forma en que los hablantes perciben el significado de su propia lengua y de las lenguas de otros pueblos, se examina también el contexto sociolingüístico e histórico más amplio, así como el contexto del "sistema mundial", es decir, los procesos sociales que operan a nivel global.

\section{El purismo lingüístico y la ideología de la cultura de las lengua estándar}

Según Bugarski (1996 [1986]: 100), el purismo lingüístico se puede definir como "[...] un sentimiento común de que [...] la lengua estándar debe preservarse a toda costa en una forma máximamente pura, lo que con frecuencia significa protegerla del cambio y, en particular, de los efectos nocivos de otros idiomas." 27 Teniendo en cuenta el hecho de que todas las lenguas cambian inevitablemente a través del contacto de sus hablantes con hablantes de otros idiomas (Langer and Davis 2005: 11), podemos decir que, desde el punto de vista lingüístico, el concepto de la "pureza" de una lengua es muy problemático. En realidad, este concepto representa un elemento de la lingüística popular, o sea, de "[...] las reacciones populares a los fenómenos lingüísticos", que "son anónimas por origen y en gran parte inconscientes [y que] se transmiten de una generación a otra [...]" "28 como elementos de los modelos culturales de la comunidad en cuestión (Bugarski 1996 [1986]: 83).

En este sentido, el purismo lingüístico no puede interpretarse fuera del marco de la ideología del prescriptivismo lingüístico y los modelos culturales de la lengua estándar (Geeraerts 2003), que a partir del siglo XVIII en gran parte del mundo eurocéntrico ha funcionado como el marco principal de la comprensión del papel del lenguaje en la sociedad. Por consiguiente, este concepto es muy a menudo referido como una de las formas del prescriptivismo, que Langer y Davis (2005: 7) determinan como un término

26 "Qualitative content analysis is a method for systematically describing the meaning of qualitative data."

27 "[...] purizam se pak očituje u rasprostranjenom osećanju da se standardni jezik mora po svaku cenu očuvati u maksimalno čistom obliku, što najčešce znači zaštititi od promena $\mathrm{i}$, naročito, od štetnih uticaja drugih jezika."

28 “Tipično anonimne po poreklu i velikim delom nesvesne, one se prenose sa jedne generacije na drugu [...]." 
más general para "[...] la actividad popular de definir y luchar por una mejor variedad de un idioma." 29 Del mismo modo, en una de las definiciones más citadas del purismo lingüístico, este fenómeno se considera como "uno de los aspectos de la codificación, la cultivación y la planificación de la lengua estándarn:

El purismo es la manifestación de un deseo por parte de la comunidad del habla (o de alguna de sus secciones) de preservar una forma de lenguaje o eliminar los supuestos elementos extranjeros o elementos que se consideran indeseables (incluidos los que se originan en dialectos, sociolectos y estilos del mismo idioma). Puede estar dirigido a todos los niveles lingüísticos, pero principalmente al léxico. Sobre todo, el purismo es un aspecto de la codificación, el cultivo y la planificación de las lenguas estándar. ${ }^{30}$ (Thomas 1991: 12, cit. en Brunstad 2003: 53)

Sin embargo, como afirma Brunstad (2003: 53), así entendido, este concepto también incluye la variación dentro de la misma lengua y por lo tanto se puede referir a "[...] un amplio discurso ideológico que cubre casi todas las nociones de corrección lingüística» ${ }^{31}$. Como de esta manera el concepto del purismo lingüístico "[...] pierde parte de su utilidad analítica" ${ }^{32}$ y como "[...] en muchos casos los mismos puristas distinguen entre el estatus del dialectalismo y el de los elementos extranjeros" ${ }^{33}$ (Brunstad 2003: 53) en este artículo nos concentraremos únicamente en aquellos casos que apuntan a "la creencia de que las palabras ( $y$ otros elementos lingüísticos) de origen extranjero representan un tipo de contaminación que mancha la pureza de la lengua» ${ }^{34}$ (Trask 2007 [1999]: 238).

Basándose en la teoría de la metáfora conceptual (Lakoff and Johnson 1980), Berthele (2010: 268) afirma que la característica común de todos modelos culturales de estandardización lingüística es la percepción metafórica del "lenguaje como un vínculo" entre sus hablantes, y "lenguaje como una barrera" para aquellos que no hablan ese

29 "Whilst the term prescriptivism is more general than purism the two are often used interchangeably when applied to the folk-linguistic activity of defining and striving for a better variety of a particular language."

30 "Purism is the manifestation of a desire on the part of the speech community (or some section of it) to preserve a language form, or rid it of, putative foreign elements or elements held to be undesirable elements (including those originating in dialects, sociolects and styles of the same language). It may be directed at all linguistic levels but primarily the lexicon. Above all, purism is an aspect of the codification, cultivation and planning of standard languages."

31 "Another problem is the danger of ending up with a concept which makes purism a broad ideological discourse covering almost all notions of language correctness."

32 "In that case, the concept loses some of its analytic utility."

33 "A third problem is that in many cases, purists actually distinguish between the status of dialectisms and the status of foreign elements."

34 "The belief that words (and other linguistic features) of foreign origin are a kind of contamination sullying the purity of a language." 
idioma. Esta interpretación nos muestra la importancia que una variedad puede tener en la construcción de la identidad colectiva de un grupo, la cual, además de la inteligibilidad mutua, depende en gran medida de las nociones populares de lo que significa "nuestro" idioma y lo que se comprende bajo su uso "apropiado". Esto supone que la cuestión de la lengua como símbolo de la identidad colectiva incluye las ideas sobre las fronteras entre "nosotros" y "los otros", es decir, sobre los elementos lingüísticos "aceptables=los nuestros" e "inaceptables $=$ los ajenos".

Concordamos con Milroy (2001: 550) cuando dice que la cuestión de qué constituye un cambio lingüístico aceptable y cuál es la influencia "perjudicial" de otras lenguas, es sobre todo una cuestión subjetiva e ideológica, condicionada por la diferencia en la comprensión de lo que significa una lengua "limpia" y "auténtica". Esto quiere decir que las actitudes puristas "[...] no ocurren automáticamente en una etapa particular del desarrollo de un idioma, sino que son desencadenados por las percepciones populares de que la lengua, por ejemplo, está en declive o está siendo corrompida»35 (Langer and Davis 2005: 3). Por lo tanto, estas actitudes aparecen como una construcción mental o un producto de la categorización subjetiva (Brunstad 2003: 54), o sea, representan un reflejo de la realidad extralingüística en la que vive una comunidad lingüística dada y no pueden ser interpretadas independientemente del contexto de otras ideologías lingüísticas y extralingüísticas. Aquí nos referimos particularmente a la ideología de la lengua estándar y la ideología del nacionalismo, que se basa en la idea romántica de que una lengua es la expresión del ser colectivo de una comunidad étnica, por lo que "defender el lenguaje común contra las influencias extranjeras (palabras de préstamo, básicamente) es al mismo tiempo una defensa de la identidad cultural de las personas" ${ }^{36}$ (Geeraerts 2003: 49).

En otras palabras, según sostiene Brunstad (2003: 57), "la calidad de la pureza no se da de antemano, sino que se construye dentro de la interacción social", ${ }^{37}$ es decir, mediante la operación de las funciones sociolingüísticas de separación y unificación. Así, dentro de la ideología del purismo lingüístico todos aquellos elementos que se consideran "inauténticos" y no pertenecientes a la lengua, desempeñan la función de separación, es decir, distinción, y pueden ser utilizados para “[...] definir las fronteras lingüísticas, o al menos indicar el hecho de que esas fronteras lingüisticas existem, ${ }^{38}$ (Brunstad 2003: 57). Por otro lado, lo que se considera "auténtico" se percibe como una base para la unificación, la comunión y la pertenencia a un grupo lingüístico en particular. Estas

35 “Purism does not occur automatically at any particular stage in the development of a language, but is rather triggered by folk-linguistic perceptions, for example that the language is going into decline or is being corrupted."

36 "Defending the common language against foreign influences (loan words, basically) is at the same time a defense of the cultural identity of the people."

37 "The quality of purity is then not given in advance, but constructed within the social interaction."

38 "On that account, the contaminated may also define language borders or at least mark the fact that there are language borders." 
funciones de separación y unificación corresponden a lo que hemos definido como tácticas intersubjetivas de distinción y adecuación (Bucholtz and Hall 2004, 2005, 2008), mientras que el tema de la "pureza" lingüística y formas de lenguaje "auténticas", así como la cuestión de quién tiene el derecho o la legitimidad para determinar los límites entre "lo aceptable" y "lo inaceptable" se refieren a las tácticas de autentificación y desnaturalización, o sea, legitimación y deslegitimación. En este trabajo, la ideología del purismo lingüístico expresada a través de las actitudes lingüísticas de los miembros del grupo virtual Ladinokomunita será interpretada precisamente desde el punto de vista del funcionamiento de las mencionadas tácticas de intersubjetividad.

\section{La ideología del purismo lingüístico dentro del grupo Ladinokomunita}

Según Neustupný (1989: 217), ues interesante notar que la depuración de las palabras extranjeras a menudo se limita solamente a los préstamos de un idioma en particular. ${ }^{39}$ En este sentido, refiriéndose a la práctica lingüística en el grupo Ladinokomunita, Rachel Amado Bortnick (2004: 8) destaca que “los problemas más persistentes provienen de la intrusión del castellano moderno, principalmente en la ortografía, pero también en el vocabulario y la sintaxis.” ${ }^{40}$ Nuestro análisis también muestra que, según la mayoría de los miembros, lo esencial en la preservación del judeoespañol es insistir en su uso "auténtico" y distinguirlo del español moderno, aunque, como veremos más adelante, los miembros del grupo consideran que este no es el único idioma de cuyos elementos hay que "depurar" la variedad étnica de los sefardíes.

En los primeros meses los administradores subrayan que la política lingüística del grupo está dirigida a preservar el carácter peculiar de la variedad judeoespañola, añadiendo que el español moderno no es bienvenido y que todos sus rasgos serán transformados en "buenos ejemplos en ladino":

\section{Ejemplo $\mathrm{n}^{2} 1$}

Fecha: 25 de marzo de 2000

Tambien rogimos no eskrivir en Kasteyano (Espanyol moderno) porke es el buto de Ladinokomunita ayudar a todos a embezarsen o mejorar sus Judeo-Espanyol (Ladino) teniendo delantre de eyos buenos enshemplos del Ladino. Es por esto ke mozotros, kuando djuzgamos rekomendable, redaktamos los mesajes korijando la ortografia i otros aspektos del mesaje. De este modo, el mizmo autor de la letra

39 "It is interesting to note that the purging of foreign words is often limited to loans from a particular language only."

40 "The most persistent problems come from the intrusion of modern Castilian, mostly in orthography, but also in vocabulary and syntax."

BEOIBERÍSTICA Vol. II / Número 1 (2018) | 251-285 
puede ver las korreksiones i ansina mejorar sus konosimientos. ${ }^{41}$

Esta resistencia al uso del español moderno también se nota en los mensajes más recientes. Apuntando a dos palabras específicas en uno de los mensajes enviados, un miembro señala:

\section{Ejemplo $\mathrm{n}^{\circ} 2$}

Fecha: 24 de abril de 2012

Kero saver si veramente los biervos eskritos en letras majuskulas estan en djudeoespanyol o pueder ser son espanyol moderno. Si es espanyol moderno komo esto pensando, Kale azer atansion i no mesklar las dos linguas, azeremos el esforso de mantener biva la lingua ma no karishtereando/mesklando la lingua djudeo espanyola $[\ldots]$

Estos dos ejemplos indican que la idea de la "protección" de la lengua debe ser vista desde la perspectiva de la revitalización del judeoespañol como una variedad minoritaria en peligro, o sea, como una lengua distintiva de los judíos sefardíes. En otras palabras, los miembros del grupo Ladinokomunita hoy en día como el mayor peligro ven el dominio del español estándar, bajo cuya influencia los hablantes del judeoespañol recurren frecuentemente a las tácticas de disipación, es decir, reducen o eliminan las características lingüísticas judeoespañolas para acercarse a esta prestigiosa lengua (Romero 2015: 59). Por lo tanto, a menudo se insiste en la distinción entre "el idioma de la diáspora judía" y el español moderno:

\section{Ejemplo $n^{2} 3$}

Fecha: 25 de noviembre de 2015

Esto d'akordo kon [nombre omitido] kuando dize ke: ..; Kreygo ke kuando inkorporamos tantas palavras del espanyol moderno al ladino, ayudamos a avansar la muerte de esta lingua ke ya se topa kaji en la foya. No sera mas la lingua de la diaspora djudia.

Los párrafos citados nos muestran que la ideología purista en el caso de los miembros del grupo Ladinokomunita refleja la percepción de los hablantes de "[...] que su lengua está en decadencia [...] [y de] que está amenazada por las influencias extranjeras y modernizadoras [...]" ${ }^{42}$ (Langer y Davis 2005: 1).

${ }^{41}$ Todos los ejemplos en este documento son enumerados en su forma original, sin ninguna intervención en el campo de la ortografía o la gramática.

42 " $[. .$.$] that the state of their language is in decline [...] that it is threatened by modernizing and$ foreign influences [...]." 
Dado que el resultado del contacto entre diferentes idiomas se observa primeramente en el nivel del vocabulario (Thomas 1991: 12, cit. en Brunstad 2003: 54), la preocupación por la preservación de la lengua judeoespañola se refiere principalmente al uso de los préstamos léxicos. En este sentido, es ilustrativo el ejemplo de la palabra española "hola". Según una de las moderadoras del grupo, un cierto número de miembros de los países de habla hispana utiliza este saludo, para el cual, como ella destaca, no existe una palabra equivalente en el judeoespañol.

\section{Ejemplo $n^{9} 4$}

Fecha: 1 de febrero de 2005

Lo ke vos kero demandar es: Siendo ke el biervo no es Ladino, mozotros moderadores/as devemos kitarlo o trokarlo, o no es emportante si lo deshamos? Lo ke dizen la mayoriya lo vamos azer.

El mayor número de respuestas se posicionó en la línea ideológica del purismo lingüístico:

\section{Ejemplo $n^{2} 5$}

Fecha: 2 de febrero de 2005

[...] si una palavra se uza oy no kere dizir ke esta en muestra lingua. Oy entra "hola", amaniana entrara otra palavra de otras linguas.

\section{Ejemplo $\mathrm{n}^{0} 6$}

Fecha: 3 de febrero de 2005

Kitalo: komo yo veyo este "Forum" si esta enchendo de palavra ke nunka avia sentido antes de enkontrarme kon espanyoles avlantes (entiendo kastiliyano i no djidio) i una es "hola", kuando se puede uzar la ekspresion "ke haber", halis sefaradia. Si keremos konservar el "djidio"/ djudezmo ke avlavan los muestros, mizmo kon sus diferensias dialektales, uzaremos palavras autentikas (o otentikas) $[\ldots]$.

\section{Ejemplo $n^{0} 7$}

Fecha: 3 de febrero de 2005

Kuando yo vo empesar a eskrivir una letra o un texto en espanyol o en ladino, si yo meti un ola para mi ya no me siento ke es esta letra mas en mi lingua ladino, me sienteria ke esta letra es vinida de los paises latinos o yo la kompozi para un amigo del Sud Amerika o la Espanya i no para los muestros [...].

\section{Ejemplo $\mathrm{n}^{\circ} 8$}

Fecha: 3 de febrero de 2005 
I de mi vanda lo ke kreigo lo mijor, es muestros rekodros en este senzo. Esto mos esklarese de la maraviya ke muestra kultura es unika, i en este senzo,tenemos unos uzos i kostumbres, ke son alavados entre los puevlos... Esto pensando i me viene al meoyo komo era en la famiya i los amigos. Partajo a lo maximalo, los saludes de uzo komo "Ke Haber? Porke lo sinti siempre!" [...] Por esto, yo kreigo ke iKe Haver! es el mijor de los saludes;no tengo nunka sintido "ola". Ma komo disheron, no savemos el dia de amanyana kualo se va trokar en muestra lingua...

\section{Ejemplo $n^{9} 9$}

Fecha: 3 de febrero de 2005

Yo penso ke el saludo de 'Ola' o 'Hola' es enteramente de el Castellano i no merese ajustar a muestra lengua. Mosotros puedemos dezir 'Saludes' o 'Ke Haber' ke son sugaramente Djudeo-Espanyol. [...] Es verda ke el Castellano es muestra 'madre lengua' ama se keremos fraguar muestra lengua, se kere echo kon buen pensar. Es verda ke tenemos munchas palavras de otras lenguas, komo Turko, grego, ebreo, Fransez, ama estas palavras son de 'kada dia' por munchos anyos....no de oy.

\section{Ejemplo $\mathrm{n}^{\mathrm{2}} 10$}

Fecha: 4 de febrero de 2005

Mientres ke por dizir "ola" yay komo SALUDOS, KOMO ESTASH TODOS, KERIDOS TODOS... etc. Siempre devemos de mirar a todar una palavra ke se uzava antes [...]. Pensa bueno antes de eskrivir si una palavra ke vozotros "los espanioles avlantes" uzash siempre ,es uzada por todos LOS MUESTROS.

En estos ejemplos podemos ver que los miembros marcan claramente el límite entre el español moderno como "muestra 'madre lengua'» (ejemplo no 9) o el idioma de "un amigo del Sud Amerika o la Espanya" (ejemplo n 7), por uno, y "muestra lingua" (ejemplo no 5), conocida como el "djidio" o "djudezmo" (ejemplo no 6), por otro lado. Para preservar esta frontera utilizan la táctica de desnaturalización de la palabra "hola" como un vocablo que no pertenece al corpus "auténtico" del idioma judeoespañol.

Como afirman numerosos autores, una de las características clave de la ideología purista es "[...] la interpretación del cambio del lenguaje como declive, que a su vez involucra el mito purista de la 'edad de oro' [...]"43 (Hohenhaus 2005: 205), es decir, el período en el pasado en el cual, como creen los puristas, el lenguaje se usó en una forma completamente "pura" y correcta (Milroy y Milroy 1999: 40). En los ejemplos citados vemos que los activistas de la lengua judeoespañola en el grupo Ladinokomunita recurren a la tradición como el modelo para el uso lingüístico "correcto" y que, de acuerdo con el

43 " [...] interpretation of language change as decline, which in turn involves the 'Golden Age' myth of purism [...]." 
principio "más viejo = mejor» (Hohenhaus 2002: 167), consideran que al buscar palabras "auténticas" uno debe volverse al pasado y a los "recuerdos" (ejemplos $n^{\circ} 6,8$ y 10). Lo que es importante subrayar es el hecho de que, aunque reconocen el carácter "híbrido" 0 "mixto" de su variedad étnica, los miembros del grupo autentifican solo aquellos préstamos legitimados por la continuidad histórica, pero no aquellos que se incorporan a la lengua en el tiempo presente (ejemplos $n^{\circ} 5$ y 9). De la misma manera, uno de los miembros enfatiza la necesidad de una clara distinción, no solo en relación con el castellano, sino también con todas las lenguas españolas:

\section{Ejemplo $n^{0} 11$}

Fecha: 5 de febrero de 2005

No es porke las linguas madres de los djudesmos son las espanyolas (kastelyano, katalan, ets) ke devemos siempre, komo dezean siertos miembros de aki, tomar palavras espanyolas. Los Espanyoles mos echaron de Espanya kon una punta de pye, i nos tenemos dinguna devda verso eyos i sus linguas. La rikeza i la savrozor de muestros djudesmos viene djustamente de lo ke travimos del uno i del otro: kuando digo de uno ke tiene muncho benadamlik, ni es palavra ebrea, ni es palavra turka, ni es palavra espanyola. Ama es halis palavra de los muestros, i solo de los muestros, i me agrada por esto mismo. Todo esto para vinir a kualo? Para dar mi idea a mi: ke kada uno aga el esfuerso de bushkar a akodrarse komo dizia su vava, i si se akodra, ke diga ansina.l si no se akodra o si la koza es mueva komo el e-mail... ke diga e-mail. Ama si se akodra ke su vava no dizia "ola" ama dizia saludos, ke diga saludos, es mijor ke ola.

Sin embargo, como ya se ha señalado, la cuestión de "lo puro" y "lo impuro" en una lengua es, ante todo, una cuestión ideológica. En consecuencia, la idea de la "pureza" de un idioma y la existencia de sus formas "auténticas" puede variar de un hablante a otro. Aunque, como hemos visto, de acuerdo con la comprensión de "la autenticidad" como un valor histórico, o sea, un valor más o menos permanente (Coupland 2010: 104), en la mayoría de las respuestas el vocablo español "hola" fue marcado como una palabra "inauténtica" e "inaceptable", nuestro análisis ha demostrado que un cierto número de miembros la cuestión de "lo auténtico" y "lo aceptable" en una lengua percibe como el resultado de un acuerdo o un consenso social (Coupland 2010: 104). De ahí esta actitud:

\section{Ejemplo no 12}

Fecha: 4 de febrero de 2005

Kreygo ke todas la linguas modernas tyenen kontakto kon otras, si no mira el djudeo-spanyol de Ladinokomunita kon sus biervos turkos, franseses, italianos, anglezes i otros. Los djidyos kuando arivaron a las Amerikas, mas muncho ande se avla espanyol, tambyen aresivyeron algunas palavaras populares, es normal i esto arrikese a la lingua, [...]. Tampoko no kreygo ke uzar esta palavra (ola/hola) en 
ladino kitaria nada de esta ermoza lingua,tambyen kreygo ke una lingua biva syempre esta akseptando [...] muevas palavras, aun manteniendo las viejas. Muevos sinonimos visten $\mathrm{i}$ azen mas ermoza a la lingua. I kon pedron (o PARDON), ama asta agora no meldi denguna letra de ladinokomunita ande se tope la solo lingua djudeo-spanyola de los viejos, i sin palavras muevas, pensa solo a la palavra komputadora/kompyuter, ets.

Estos diferentes puntos de vista sobre el tema de la "autenticidad" y la "aceptabilidad" plantean la cuestión del uso de las tácticas de legitimación y deslegitimación, como los procesos en los que a ciertas instituciones o individuos se les otorga la autoridad para determinar los límites de "lo aceptable" e "inaceptable" en un idioma. Ya se ha destacado que el judeoespañol es una lengua minoritaria en peligro de extinción, cuyos hablantes se comunican cada vez más en el contexto virtual y cada vez menos en el contexto físico, y que (todavía ${ }^{44}$ ) no tiene una academia que se pueda ocupar de diferentes cuestiones lingüísticas. Este hecho nos permite afirmar que los administradores y los moderadores del grupo Ladinokomunita en su esfuerzo para promover el uso de esta lengua actúan desde la posición de los líderes lingüísticos. La noción de liderazgo lingüístico Filipović (2016: 627) define como un ejemplo de la planificación lingüística de abajo hacia arriba, basado en la confianza y la solidaridad entre los miembros de una comunidad, que intentan transferir la práctica lingüística "emergida" a un nivel más amplio de la comunidad de cuestión. En otras palabras, estos activistas "[...] intentan influir en los hablantes existentes, anteriores o potenciales del idioma para que continúen utilizando el idioma [... y], ahora son comúnmente alentados por organizaciones supranacionales y por la creciente aceptación de puntos de vista asociados con los derechos lingüísticos" "45 (Spolsky 2009: 204).

En este sentido, a excepción de la regla indiscutible sobre el uso exclusivo del judeoespañol (y eso de acuerdo con el sistema ortográfico de la revista $A k i$ Yerushalayim ${ }^{46}$ ), en el proceso de selección de formas lingüísticas "aceptables" los

44 Los días 19 y 20 de febrero de 2018 se celebró en Madrid una convención académica del judeoespañol, durante la cual se llegó al compromiso de acuerdo sobre la creación de la Academia Nacional del Judeoespañol en el estado de Israel, cuyo trabajo se basaría en la colaboración con la Real Academia Española (RAE) y la Autoridad Nasionala del Ladino (ANL). Como lo demuestra nuestra reciente encuesta, la ANL, como institución que desde 1997 promueve el ladino en Israel, entre un cierto número de los sefardíes en diáspora no es aceptada como una autoridad en el campo de la política y planificación lingüísticas.

45 "[...] they attempt to influence existing, former, or potential speakers of the language to continue its use [...], they are now commonly encouraged by supranational organizations and by the growing acceptance of views associated with language rights."

${ }^{46}$ La ortografía de esta revista en judeoespañol, que estuvo activa durante el período de 1979 a 2016, según el editor en jefe, "[...] es bazada sovre un alfabeto fonetiko, en el kual kada sono es reprezentado por una letra o un par de letras, i kada letra o par de letras reprezenta un solo sono" (Shaul 2004). Este sistema fue elegido con el fin de representar fielmente la fonética del idioma judeoespañol y 
moderadores procuran tomar todas las decisiones llegando a un consenso entre los miembros interesados, lo que representa una de las principales características de una comunidad de prácticas (Dodsworth 2014: 270). Esto, por supuesto, según lo confirmado por nuestra encuesta, no significa que entre los miembros del grupo no haya expectativas sobre la formación de instituciones autorizadas que se ocupen de la estandarización y preservación del idioma judeoespañol. Hasta ese momento, los moderadores y los miembros del grupo en el intento de legitimar ciertas formas lingüisticas recurren al procedimiento de "la historización" (Milroy 2001: 548). Por lo tanto, la actitud de la mayoría de los miembros que deslegitiman la mencionada palabra "hola" como una palabra "pura" judeoespañola desde la perspectiva de su "inhistoricidad" se ve resumida en la siguiente posición de una de las moderadoras del grupo:

\section{Ejemplo $n^{2} 13$}

Fecha: 4 de febrero de 2005

La grande parte de las repuestas disheron "Hola no es muestra lingua", i no la adoptaremos. [...] Kon estas diskusiones mos ambezimos ke algunos sefaradim, sovre todo en la Amerika, lo uzaron muncho, i se puede konsiderar Ladino. En Turkia uzan "merhaba" muncho, ma todos saven ke esto es en turko, i no Ladino. (Muestras madres o nonas nunka dizian "merhaba". Si, algunas vezes tenemos menester de tomar del espanyol, ma solo kuando no tenemos biervo ekivalente en Ladino.) En todo kavzo, de estas diskusiones espero ke los "castellano-avlantes" ya vieron ke tenemos munchos biervos i frazas en Ladino puro para saludar, ke es preferable siempre ke de uzar "hola". I si alguno se olvida, i lo uza, lo vamos a deshar.

El ejemplo anterior nos muestra de nuevo que ciertas palabras de otras lenguas, aunque usadas por los sefardíes, como, por ejemplo, "merhaba" ("hola"' en turco) no se consideran palabras judeoespañolas "puras" y "auténticas". Por otro lado, aquí cabe subrayar una vez más que muchas palabras del origen turco ( $y$ no solo turco) a lo largo de la historia han sido adoptadas como parte integral del corpus léxico judeoespañol y que muchos de los hablantes todavía las utilizan sin ser conscientes de su origen:

\section{Ejemplo $n^{\circ} 14$}

Fecha: 2 de junio de 2000

Ayde es turko!? Yo dicho esto tantos tiempos i no savia ke no es Ladino.

"[...] meter fin al estado de anarshia i konfuzion ke reyna en este kampo desde mas de 70 anyos [...]", o sea, desde el momento en el que los sefardíes abandonaron el uso de las letras rashi y empezaron a utilizar diferentes alfabetos bajo la influencia de las lenguas estándar de diferentes estados nacionales en los que vivían. 
Sin embargo, nuestro análisis sugiere que en los últimos años algunos miembros creen que, para lograr una mejor inteligibilidad mutua entre los miembros de esta comunidad de práctica, es necesario "eliminar" las palabras que provienen del idioma turco. Como uno de los argumentos para tales actitudes aparece el hecho de que el uso de estas palabras es característico solo para aquellos sefardíes cuyos antepasados vivieron en los territorios de la Turquía actual:

\section{Ejemplo $\mathrm{n}^{\mathrm{Q}} 15$}

Fecha: 9 de mayo de 2012

kreigo ke es mijor si todos eskrivish sin biervos en Turko, de ke no vos entendemos, ni entendemos los biervos ke se eskriven muchas vezes en el Amaneser, i otras publikasiones.

\section{Ejemplo $n^{2} 16$}

Fecha: 10 de mayo de 2012

Miran kuando eskrivo mis mesajes, no ay una palavra Turka. Es ke no me entendesh? Porke eskrivir a una lingua ladina biervos Turkos? Muestra lingua es un dialekto de ladinofranses espanyol [...] i no del turko. Por favor no me efasen el Hola de mi mail. yo lo kero dizir de este modo.

A partir de estos mensajes se puede entender que, por un lado, la "depuración" de la lengua de los turcismos implica una distinción muy clara en relación con el turco, como una lengua no perteneciente al corpus de las lenguas romances (“ladino, franses, espanyol", ejemplo $n^{\circ} 16$ ), mientras que, por otro lado, promueve la adecuación del grupo, es decir, el acercamiento de todos los miembros, independientemente de si su variedad del habla se desarrolló bajo la influencia del turco u otro idioma. Esta actitud se posiciona en la línea ideológica del "purismo romance" (ver también el ejemplo $n^{\circ} 22$ ), que Şaul (2013: 222), en el contexto de las polémicas sefardíes de finales del siglo XIX y principios del siglo XX, define como el tipo de purismo "[...] basado en la sensación de que la frontera entre la lengua vernácula y las lenguas europeas [o sea, romances] era permeable, mientras que la frontera con las lenguas de contacto locales, como el turco y el griego, y con [...] el hebreo, se tenía que mantener como impenetrable.»47 De ahí la insistencia en el elemento hispano como la base de la unidad colectiva y el replanteamiento de la cuestión de la palabra "hola", que, como hemos visto, como uno de los lexemas más reconocibles españoles, provocó un debate unos años antes.

47 "Romance purism was based on the feeling that the boundary between the vernacular and European languages was permeable whereas the boundary with local contact languages such as Turkish and Greek and with [...] Hebrew were to be maintained as impenetrable." 
Si nos fijamos en la idea purista de que la lengua es algo “[...] que existió en una forma pura y no corrompida en algún momento de la historia" ${ }^{48}$ (Langer and Davis 2005: 9), debemos preguntarnos si y en qué período de la historia los miembros del grupo sefardí están buscando esta "forma no corrompida" del idioma judeoespañol. Como hemos visto en los ejemplos anteriores, su deseo de preservar las formas "auténticas" de la lengua les hace mirar hacia el pasado, o sea, hacia la época en que esta lengua fue utilizada por sus padres y sus abuelos. Sin embargo, el hecho de que después de la expulsión en contacto con otras lenguas el judeoespañol se desarrollara como una variedad independiente del español peninsular (Quintana 2010: 34) y de que fuera precisamente este contacto lo que le dio su carácter distintivo, nos sugiere que es imposible encontrar un modelo de la lengua que sea "puro" y "no corrompido" por los contactos lingüisticos. Asimismo, no hay que olvidar el hecho de que esta variedad se desarrolló como una lengua pluricéntrica, lo que significa que hubo diferentes normas regionales que se constituyeron bajo diferentes influencias en torno a varios centros económicos, políticos y culturales en los que los sefardíes vivieron en los tiempos modernos (Quintana 2010: 42).

Por otro lado, las actitudes según las que el idioma se debe "purificar" de las palabras turcas y acercar a la herencia hispana, nos devuelve al período anterior a la expulsión, cuando, como afirma Díaz-Mas (2006 [1986]: 115), el judeoespañol todavía no era una lengua distintiva, y cuando, con menores variaciones étnicas, los sefardíes hablaban el mismo idioma que sus vecinos no judíos. Esto nos remite a la idea de que la "edad de oro" (Hohenhaus 2005: 205), que presupone un uso lingüístico "ideal" y "auténtico", en realidad no existe, es decir, de que representa solo una construcción conceptual y subjetiva (Brunstad 2003: 54), que, como hemos visto en los ejemplos anteriores, puede variar de un hablante al otro.

A pesar de las actitudes puristas mencionadas, desde los principios de la existencia del grupo los miembros parecen ser plenamente conscientes de que la lengua judeoespañola, como todos las lenguas, se originó como un producto de contacto lingüístico y que en la actualidad precisamente a través del contacto con otras lenguas debe ser modernizada si se quiere asegurar su futuro en la sociedad contemporánea. Por lo tanto, los elementos de la ideología del purismo lingüístico en este caso pueden ser explicados como un intento de encontrar el compromiso entre la preservación de la distintividad etnolingüistica y la imprescindible adaptación de la lengua a "las necesidades de la cultura urbana" (Bugarski 1996 [1986]: 173), lo que se manifiesta en la opinión de que a veces es necesario tomar palabras de otros idiomas, "ma solo kuando no tenemos biervo ekivalente en Ladino" (ejemplo no 13). Según Spolski (2004: 22), "el purismo se vuelve importante [precisamente] durante el período de cultivación y modernización del

48 "[...] linguistic folk consider such items as English or German or Dutch to be things [...] which existed in a pure and uncorrupted form at some stage in history."

BEOIBERISTICA Vol. II / Número 1 (2018) | 251-285 
lenguaje, proporcionando un criterio para la selección del nuevo léxico."49 Por consiguiente, dado el hecho de que los miembros de la comunidad sefardí viven dispersos en diferentes Estados nación, y de que eso complica la comunicación cotidiana que de manera espontánea podría regular las normas de uso del lenguaje, algunos de los miembros se preguntan qué criterios de selección de recursos lingüísticos deben ser utilizados en el proceso de modernización:

\section{Ejemplo $n^{\circ} 17$}

Fecha: 27 de noviembre de 2015

Lo ke dizes es interamente djusto, una lingua ke bive konose naturalmente modifikasyones. Ma ke son las modifikasyones ke se pueden asperar. Adjustar byervos amerikanos/ingleses? portugezos? francezes? ebreos? sudmaericanos? italyanos? rusos? Komo se va deskojer? se va romper in pedasikos asigun el lugar o paes. [...] Oy in las diasporas no kedo territoryo sefaradi. De mas se kere munchos ke la avlen, dizgrasyamente no es el kavzo.

La inexistencia del ya mencionado "territorio sefardí, o sea, el carácter diaspórico de esta comunidad, determina en gran medida el marco ideológico en el que se intenta reconstruir la identidad sefardí distintiva sobre los fundamentos de la lengua judeoespañola. Este proceso no puede ser interpretado independientemente de su relación con las ideologías de la modernidad, con referencia particular a la ideología de las culturas de lengua estándar (Milroy 2001; Filipović 2015) ${ }^{50}$ que hoy entre los grupos minoritarios aparece a través de una forma renovada de "la valoración romántica de la vernaculación lingüística" (Filipović 2015: 21). Con esto queremos decir que la tendencia postmodernista de encumbrar las variedades vernáculas de estos grupos al nivel de la lengua estándar "[...] ya no está asociada con la formación de los Estados nación, sino con la preservación de las identidades étnicas de las comunidades minoritarias dentro de los estados europeos ya existentes "51 (Filipović 2009: 76) o, podemos añadir, en el caso de la comunidad sefardí y otras comunidades diaspóricas, dentro de los uespacios sociales transnacionales" (Rudometof 2005: 120), como, por ejemplo, Internet. En estas circunstancias el idioma se convierte en uno de los pilares centrales de la identidad étnica, $y$, por consiguiente, todas las intervenciones con respecto a su preservación y adaptación a las necesidades de la sociedad moderna se consideran muy cuidadosamente:

49 "Purism becomes important during a time of language cultivation and modernization, providing a criterion for the choice of new lexicon."

50 Para las ideologías lingüísticas de la modernidad en el contexto de la comunidad sefardí en el Oriente ver, por ejemplo, Filipović y Vučina Simović 2014.

51 “Novi proces lokalizacije, međutim, više nije u vezi sa stvaranjem država-nacija, već sa očuvanjem etničkih identiteta manjinskih zajednica na teritorijama već postojećih evropskih država." 


\section{Ejemplo $n^{\circ} 18$}

Fecha: 11 de mayo de 2000

Si mozotros keremos ke el Ladino sovrebiva lo tenemos ke avlar, i estimular a otros a avlarlo, uzando todos los mezos disponibles. I kualo mezo mejor ke muestro kazaliko elektroniko, Ladinokomunita? Ma, en avlandolo, si no observamos siertas normas, sierta reglas, la linga ke se perpetua devendra una mezkolansa de korrupsiones. Por esto kreo ke devemos de esforzarmos por evitar el uzo de palavras de otras linguas, a menos ke estas sean valutozas por reprezentar konseptos muevos (espesialmente importante en la teknolojia) i ke por amor del futuro de muestra lingua mos tomemos la pena de apanyar el diksionario i bushkar una palavra apropida del Ladino en vez de meter en la korrespondensia una palavra ingleza o franseza. Kreo yo ke kuando la palavra dezeada no se topa, se deve tomarla emprestada del Kasteyano, la madre de la lingua muestra. De este modo se mantendra el karakter i savor espanyoles de eya.

\section{Ejemplo no 19}

Fecha: 6 de febrero de 2005

[...] kreygo yo ke el Kastilyano es mas una "lingua-sovrina" ke una "lingua-madre" del muestro espanyoliko. Kreygo yo ke en el manko de muevos biervos para muevas ideas, podriamos tenerlos adaptados de

* biervos ladinos antiguos

* ivrit

* kastilyano del siklo XV

* linguas orientales donde biviron los muestros

Por ultima opsion, del ingles i del kastilyano moderno.

Estos dos ejemplos sugieren que en el proceso de modernización y enriquecimiento léxico hay que recurrir a los modelos lingüísticos del pasado común, es decir, a las fuentes lingüísticas "auténticas", que preservarían la distintividad de la lengua de la comunidad sefardí. En este sentido, en primer lugar se piensa en la tradición cultural judeoespañola, y luego también en otras variedades que a lo largo de la historia marcaron el carácter distintivo del idioma judeoespañol en el Oriente: el hebreo, el castellano preclásico y, finalmente, las lenguas de los pueblos con los que los sefardíes convivieron después de la expulsión (ejemplo n 19). Por otra parte, es muy curioso que, cuando entre las fuentes existentes no es posible encontrar una palabra apropiada para expresar nuevos conceptos de la cultura urbana, los miembros consideren necesario recurrir al español moderno como "la madre de la lingua muestra" (ejemplo $\mathrm{n}^{\circ}$ 18) 0 como una "lingua sovrina" (ejemplo $\mathrm{n}^{\circ}$ 19). La idea de que de esta manera se pueden preservar "el karakter y savor espanyoles" (ejemplo $n^{\circ}$ 18) de la lengua judeoespañola apunta a la importancia del origen común de estas dos variedades en el proceso de adecuación de esta comunidad étnica. Si la adecuación se entiende como "[...] la 
construcción de una similitud contextual suficiente entre individuos o grupos”.52 (Bucholtz 2003: 408), entonces el español moderno puede ser entendido como un contexto que proporciona esta "similitud suficiente", o sea, como un elemento de la cohesión colectiva en condiciones de la inexistencia de la comunidad sefardí en el sentido tradicional y la dispersión geográfica de sus miembros.

Esta posición ideológica de un gran número de miembros del grupo fue confirmada por los resultados de la encuesta:

Tabla $\mathrm{n}^{\circ} 1$

\begin{tabular}{|l|c|c|}
\hline $\begin{array}{c}\text { Según usted, ihay que } \\
\text { introducir préstamos } \\
\text { léxicos de otras lenguas } \\
\text { para las palabras que no } \\
\text { existen en ladino/judeo- } \\
\text { español? }\end{array}$ & \multicolumn{2}{|c|}{ Resultados de la encuesta } \\
\hline Respuestas & Número de respuestas & $\%$ \\
\hline Sí & 40 & 91 \\
\hline No & 3 & 6,8 \\
\hline Otras respuestas & 1 & 2,2 \\
\hline Total & 44 & 100 \\
\hline
\end{tabular}

Tabla $\mathrm{n}^{\circ} 2$

\begin{tabular}{|l|c|c|}
\hline \multirow{2}{*}{$\begin{array}{c}\text { ¿De qué lengua hay que } \\
\text { introducir estos préstamos? }\end{array}$} & \multicolumn{2}{|c|}{ Resultados de la encuesta } \\
\hline Respuestas & Número de respuestas & $\%$ \\
\hline Español & 25 & 62,5 \\
\hline Hebreo & 2 & 5 \\
\hline Español y hebreo & 2 & 5 \\
\hline Español, hebreo, inglés & 1 & 2,5 \\
\hline Francés & 3 & 7,5 \\
\hline No importa & 6 & 15 \\
\hline Otras respuestas & 1 & 2,5 \\
\hline Total & 40 & 100 \\
\hline
\end{tabular}

Las respuestas muestran que la gran mayoría de los miembros (91\%) está de acuerdo con 52 "[...] the construction of contextually sufficient similarity between individuals or groups." 
la introducción de los préstamos en los casos en que una palabra en particular no existe en el idioma judeoespañol (ver Tabla $n^{\circ} 1$ ). Por otro lado, la mayoría de aquellos que no se oponen a la adopción de palabras de otros idiomas (62.5\%) consideran que estos préstamos deben tomarse primero del idioma español (ver Tabla no 2). Las justificaciones de esta respuesta indican que esta lengua se percibe como la base sobre la cual se originó la variedad judeoespañola:

\section{Ejemplo $n^{2} 20$}

\section{Cuestionario n. ${ }^{\circ} 17$}

Oy en dia, es mas lojiko de tomar prestamos de la lingua en ke se baza el JudeoEspanyol. En el pasado, el mundo no tenia una komunikasion global komo ay oy, alora los prestamos se tomavan de las linguas ke estavan serka. Oy no tenemos este problema.

\section{Ejemplo n 21}

Cuestionario n. ${ }^{\circ} 30$

Los emprestamos del turko, grego, fransez etc. fueron tomados en epokas en las kualas la mayoria de los sefaradis tenian kontaktos diarios kon estas lenguas, lo ke no es mas el kavzo oy. Se podria tomar del ebreo, ma si keremos ke el ladino sea una lengua avlada, meldada $\mathrm{i}$ entendida por la mayoria de los sefaradis en el mundo, kreo ke es del espanyol ke devemos tomar las palavras ke mos mankan, adaptandolas naturalmente a muestra fonetika.

\section{Ejemplo $n^{\circ} 22$}

Cuestionario n. ${ }^{\circ} 40$

El espanyol es la parte dominante de nuestra lengua. Pero tambien es posivle de prestar de otras lenguas romanas.

\section{Ejemplo $n^{\circ} 23$}

Cuestionario n. ${ }^{\circ} 42$

Seria un camino natural nuestros abuelos avlavan espanyol con las pocas palabras hebreas ama no keria perder lo ke oy ya esta en la lengua el poco de francés, italiano, hebreo.

En estos ejemplos es evidente que los encuestados se dan cuenta de la importancia del contexto global en el que hoy en día se lleva a cabo la comunicación en su lengua étnica (cuestionario $n^{\circ}$ 17). En otras palabras, a diferencia de las circunstancias sociolingüísticas del pasado sefardí (ver Nedović Pons 2016), el contexto del "sistema mundial" de hoy (Blommaert 2005), especialmente marcado por el uso de Internet como plataforma de comunicación global, ofrece mayores oportunidades para el encuentro con 
el español estándar, como una de las lenguas más prestigiosas del mundo y como la lengua que en el pasado sirvió de base para la construcción de la identidad sefardí distintiva. En ese sentido, en una situación donde el mayor número de los sefardíes es bilingüe o multilingüe estando en contacto diario con diferentes idiomas en función del lugar de residencia, recurrir a los préstamos españoles en ausencia de lo que los miembros del grupo consideran ser palabras judeoespañolas "auténticas", podría interpretarse como un intento de la adecuación grupal sobre la base del pasado lingüístico común. Por lo tanto, el retorno al español como fuente lingüística se autentifica como un "camino natural" (cuestionario $n^{\circ} 42$ ).

Hablando de este "camino natural" del judeoespañol, es importante citar la explicación de un miembro que cree que seguir el camino "auténtico" en el enriquecimiento del léxico significa usar los mismos principios lingüísticos utilizados por los antepasados:

\begin{abstract}
Ejemplo n 24
Cuestionario . $^{\circ} 36$

Tenemos ke pensar bien en esta kestion. Muestra lingua es una lingua kareshtereada dezde el empesijo, i deve de sigir ansina. Kuando pensamos en biervos muevos, devemos de krear biervos kon raizes en mas de una lingua relasionada kon la muestra - krear biervos kon bazas ispanikas i sufijos turkos, por enshemplo, o otra kombina depende en el konteksto. En otros biervos, tenemos ke inventar biervos segun los mizmos uzos ke muestros papus i nonas emplearon al pasado.
\end{abstract}

Dicho de otro modo, el retorno a la tradición o a las fuentes "auténticas" (Spolsky 2004: 22) se percibe aquí como un retorno al principio de la "mezcla" lingüística, sobre cuya base se formó el idioma judeoespañol como el idioma distintivo de los judíos sefardíes en el territorio del Imperio Otomano.

\title{
7. Conclusiones
}

Nuestro objetivo en el presente artículo ha sido mostrar que la ideología del purismo lingüístico entre los miembros del grupo Ladinokomunita aparece como parte del contexto postmodernista de las culturas de la lengua estándar, en el que se intenta proteger, mantener y revitalizar la lengua judeoespañola como lengua minoritaria en peligro, o sea, como un elemento importante de la identidad étnica sefardí. Partiendo de la definición constructivista según la cual la identidad étnica se (re)construye en la interacción lingüística mediante el uso de las tácticas de intersubjetividad, hemos mostrado que las discusiones y las actitudes puristas de los miembros de esta comunidad 
virtual revelan el significado que los sefardíes en la actualidad atribuyen a su idioma étnico dentro de un proceso más amplio de la revitalización y la (re)construcción de la etnicidad sefardí en el mundo contemporáneo. Este significado, como hemos podido ver, se forma en función del contexto sociolingüístico en el que hoy en día viven los sefardíes y que comprende su dispersión por el mundo entero, su integración en la sociedad secular y el uso de la lengua judeoespañola en Internet como un espacio social transnacional. En este contexto, como afirma Brink-Danan (2011: 117), "[...] la única frontera que [los sefardíes] pueden controlar es la diferencia lingüística entre ellos y los que no hablan el ladino.."53 Por lo tanto, como sugiere nuestro análisis, la preocupación por la "pureza" de la lengua judeoespañola en el grupo Ladinokomunita se percibe como un intento de preservar y defender el carácter distintivo de la identidad sefardí.

Los resultados obtenidos en esta investigación indican que la mayoría de los miembros de esta comunidad virtual de una manera muy clara buscan marcar las fronteras etnolingüísticas hacia otras lenguas, en primer lugar el español estándar, cuyo prestigio a nivel global y la similitud con el judeoespañol a todos los niveles de la organización lingüística se perciben como la mayor amenaza para el futuro de su idioma étnico. En este sentido, la insistencia en la "depuración" del judeoespañol de las influencias "nocivas" del español, es decir, en la preservación del léxico "auténtico" sefardí, se puede entender como un intento de afirmar la distintividad etnolingüística de los sefardíes.

Sin embargo, la discusión nos revela que la "autenticidad" y "pureza" del uso lingüístico son algo que no existe fuera del dominio conceptual e ideológico, sino que se forma y se cambia dentro de la negociación ideológica entre los participantes de la interacción social y puede variar de un hablante a otro:

- para unos, el uso de palabras del español moderno se ve como un uso "inauténtico", y la lengua "auténtica" y "pura" hay que buscarla en la práctica lingüística de los hablantes del pasado (de sus padres y sus abuelos), que, sin embargo, fue basada precisamente en el uso de los elementos de otras lenguas de contacto;

- para otros, hay que "depurar" el judeoespañol de los turcismos, lo que supone una "depuración" de la lengua usada por los sefardíes en el periodo otomano (o sea, en la época de formación del judeoespañol), y la vuelta al uso lingüístico anterior a la expulsión, en el que la lengua usada por los sefardíes apenas difería de aquella de sus vecinos cristianos y musulmanes;

- para terceros, la "autenticidad" supone el uso del principio de la mezcla de los elementos de diferentes lenguas con las que el judeoespañol estuvo en contacto durante su historia.

En otros términos, nuestro análisis sugiere que, por una parte, a la hora de definir lo "auténtico" los miembros del grupo se vuelven al pasado, buscando una "edad del oro"

53 " [...] the one boundary they can police is the linguistic difference between themselves and nonLadino speakers."

BEOIBERÍSTICA Vol. II / Número 1 (2018) | 251-285 
durante la cual el judeoespañol se utilizó de una manera "pura". Por otra parte, la existencia de este periodo resulta problématica, ya que el judeoespañol, como todas las lenguas, siempre se ha formado en contacto con otras lenguas.

Al mismo tiempo, parece que el purismo de los miembros del grupo Ladinokomunita no es tan "puro" y exclusivo, dado que, según los resultados de nuestra encuesta, la mayoría considera que en el proceso de introducción de palabras necesarias para la modernización y la revitalización de la judeoespañol hay que "contactar" con otras lenguas, y más concretamente, que la mejor fuente de préstamos lingüísticos es precisamente el español estándar. Como se puede entender de los ejemplos citados, esta actitud proviene de la percepción de que la herencia hispana representa el retorno a las raíces y el denominador común de los sefardíes en diáspora, sobre cuya base es posible ejecutar tanto la adecuación colectiva de esta comunidad étnica, como su distinción de otras comunidades judías. Dicho de otro modo, en el proceso de la adaptación del judeoespañol a las exigencias de la vida contemporánea de los sefardíes dispersos por todo el mundo, el español moderno se percibe como un elemento de la cohesión colectiva.

Teniendo en cuenta todo esto, podemos concluir que en el caso de la comunidad sefardí la ideología del purismo lingüístico aparece vinculada al proceso de la reconstrucción de su identidad étnica, en el que el intento de eliminar las palabras españolas, por uno, y el uso del español "en el caso de la necesidad", por otro lado, vienen formados en función de la realidad social, cultural y política y el contexto glocal en el que hoy en día viven los sefardíes. En este sentido, nuestros resultados confirman la idea de que el purismo lingüístico representa un reflejo de la realidad extralingüística de los hablantes de un idioma. Esto es aún más evidente si comparamos las actitudes puristas de los miembros del grupo Ladinokomunita con las actitudes de los sefardíes a finales del siglo XIX y principios del siglo XX, que, en el contexto de la ideología nacionalista de la lengua éstandar, consideraban el judeoespañol como un idioma "impuro" e "inauténtico", que debería ser desplazado por los idiomas "auténticos": el español, el francés, el hebreo - las lenguas oficiales de los estados en los que vivían (Vučina Simović 2011, Vučina Simović 2016: 233-271). En la actualidad, sin embargo, los sefardíes en el contexto transnacional de la sociedad postmoderna intentan preservar y revitalizar "la autenticidad" de su lengua étnica, "purificándola" (hasta cierta medida) de los elementos “inauténticos" provenientes de otras lenguas, en primer lugar del español y del turco.

Puesto que los resultados de nuestra investigación han demostrado que es imposible reconstruir "una edad de oro" en el que el judeoespañol se utilizó de una manera "pura", y que, además, pueden coexistir varias ideas sobre "la autenticidad" lingüística, esperamos que con este trabajo, en la línea de la transdisciplinariedad científica, hayamos mostrado que en el proceso de la revitalización del judeoespañol puede ser más prudente permanecer en una posición de compromiso y aceptar diversas formas de entender "lo auténtico". Después de todo, lo esencial para el futuro del 
judeoespañol no es su "pureza", sino los esfuerzos hacia la promoción de su uso en diferentes dominios lingüísticos, porque, como dice Dorian (1992: 492) sobre las lenguas en peligro: "[s]i [la lengua] nunca puede volver a ser exactamente lo que era, puede que sea algo más de lo que es ahora., ${ }^{54}$

\section{Agradecimientos}

Deseo expresar mi inmensa gratitud a Rachel Amado Bortnick y los miembros de Ladinokomunita por haberme prestado su ayuda en esta investigación.

\section{BIBLIOGRAFÍA}

Amado Bortnick, Rachel. "The internet and Judeo-Spanish: Impact and implications of a virtual community". Hilary S. Pomeroy and Michael Alpert (eds.), Proceedings of the twelfth British conference on Judeo-Spanish studies, Leiden: Brill, 2004: 3-11. Print.

Alten, Asli Mustanoğlu. "The Role of Judeo-Spanish in Sephardic Identity". M. A. thesis, unpublished manuscript, Ankara: Graduate School of Social Sciences of Middle East Technical University, 2012. Web. 21 Dec. 2015.

Bucholtz, Mary. "Sociolinguistic nostalgia and the authentication of identity". Journal of sociolinguistics, 7 (3), (2003): 398-416. Web. 10 Sep. 2017.

Bucholtz, Mary and Kira Hall. "Language and identity". Alessandro Duranti (ed.), $A$ Companion to Linguistic Anthropology, Oxford: Blackwell Publishing, 2004: 369394. Print.

-. "Identity and interaction: A sociocultural linguistic approach". Discourse studies, 7 (45), (2005): 585-614. Web. 10 Sep. 2017.

-. "Finding identity: Theory and data». Multilingua, 27 (1-2), (2008): 151-163. Web. 15 Sep. 2017.

Berthele, Raphael. "Investigations into the folk's mental models of linguistic varieties". Dirk Geeraerts et al. (eds.), Advances in cognitive sociolinguistics, Berlin / New York: De Gruyter Mouton, 2010: 265-290. Print.

Blommaert, Jan. Discourse: A critical introduction. New York: Cambridge University Press, 2005. Print.

Bornes Varol, Marie-Christine. "The Invention of Eastern Judeo-Spanish: The Betrayals of Spanish in the Re-romanization Process (End of $19^{\text {th }}$ Century) and its Consequences". Mahir şaul and José Ignacio Hualde (eds.), Sepharad as Imagined Community, New York / Bern / Frankfurt / Berlin / Brussels / Vienna / Oxford / Warsaw: Peter Lang, 2017: 163-189. Kindle Edition.

\footnotetext{
54 "If it can never again be exactly what it once was, it may yet be something more than it now is."
} 
Brink-Danan, Marcy. "The meaning of Ladino: the semiotics of an online speech community". Language \& Communication, 31 (2), (2011): 107-118. Web. 16 Jun. 2016.

Bugarski, Ranko. Jezik u društvu (drugo izdanje). Beograd: Čigoja štampa, 1996 [1986]. Štampano.

Bunis, David. M. “Modernization and the Language Question among Judezmo-Speaking Sephardim of the Ottoman Empire». Harvey E. Goldberg (ed.), Sephardi and Middle Eastern Jewries: History and Culture in the Modern Era, Bloomington, Indianapolis: Indiana University Press, 1996: 226-239. Print.

-. "The Names of Jewish languages: a taxonomy". Francesco Aspesi et al. (eds.), Il mio cuore è a Oriente: Studi di linguistica storica, filologia e cultura ebraica dedicati a Maria Luisa Mayer Modena, Milan: Cisalpino, 2008: 415-433. Print.

-. "Native designations of Judezmo as a 'Jewish Language'". Josef Tobi and Dennis Kurzon (eds.), Hikrei Ma'arav u-Mizrah. Studies in Language, Literature and History. Presented to Joseph Chetrit, Jerusalem: Carmel Publishing, 2011a: 41-81. Print.

-. "Judezmo: The Jewish Language of the Ottoman Sephardim". European Judaism, 44 (1), (2011b): 22-35. Web. 16 Jun. 2016.

-. "Twenty-First-Century Talk about Judezmo on the Ladinokomunita Website". Norich, Anita, and Joshua L. Miller (eds.), Languages of Modern Jewish Cultures: Comparative Perspectives, Ann Arbor: University of Michigan Press, 2016: 321360. Print.

Brunstad, Endre. "Standard language and linguistic purism". Sociolinguistica, 17 (1), (2003): 52-70. Web. 20 Jan. 2018.

Coupland, Nikolas. "The authentic speaker and the speech community". Carmen Llamas and Dominic Watt (eds.), Language and identities, Edinburgh: Edinburgh University Press, 2010: 99-112. Print.

Crystal, David. Language and the Internet. Cambridge: Cambridge University Press, 2001. Print.

Díaz-Mas, Paloma. Los sefardies: historia, lengua y cultura (cuarta edición). Barcelona: Riopiedras Ediciones, 2006 [1986]. Impreso.

Dodsworth, Robin. "Speech communities, social networks, and communities of practice". Janet Holmes and Kirk Hazen (eds.), Research Methods in Sociolinguistics: $A$ Practical Guide, Malden / Oxford: Wiley Blackwell, 2014: 262-275. Print.

Dorian, Nancy. C. "Purism vs. compromise in language revitalization and language revival". Language in Society, 23 (04), (1994): 479-494. Web 13 Dec. 2017.

Dženkins, Ričard. Etnicitet u novom ključu. Prev. Ivana Spasić. Beograd: Biblioteka XX vek, 2001. Štampano. [Original: Jenkins, Richard. Rethinking Ethnicity. London: SAGE Publications, 1997]

Eckert, Penelope and Sally McConnell-Ginet. "Think practically and look locally: Language 
and gender as community-based practice». Annual review of anthropology, 21 (1), (1992): 461-488. Web. 12 Jun. 2017.

Filipović, Jelena. Moć reči: ogledi iz kritičke sociolingvistike. Beograd: Zadužbina Andrejević, 2009. Štampano.

- “El judeoespañol en las culturas de lenguas estandardizadas: lenguas minoritarias dominadas e ideologías linguísticas en el siglo XXl”. Balkania, 6, (2015): 20-32. Web. 10 Aug. 2017.

- "Lingvistika i teorija kompleksnosti: jezičko liderstvo kao integralni deo jezičke politike i planiranja u 21. veku". Snežana Gudurić i Marija Stefanović (ur.), Jezici i kulture u vremenu u prostoru V, Novi Sad: Filozofski fakultet, 2016: 623-636. Štampano.

Filipović, Jelena and Ivana Vučina Simović. "Language ideologies in times of modernity: the case of the Sephardim in the Orient". Ana Kuzmanović et al. (eds.), Estudios hispánicos en el siglo XXI, Belgrado: Facultad de Filología / Čigoja, 2014: 517-545. Impreso.

Garrett, Peter, et al. Investigating Language Attitudes: Social Meanings of Dialect, Ethnicity and Performance. Cardiff: University of Wales Press, 2003. Print.

Garrett, Peter. "Language attitudes". Carmen Llamas et al. (eds.), The Routledge Companion to Sociolinguistics, London / New York: Routledge, 2007: 116-121. Print.

Geeraerts, Dirk. "Cultural models of linguistic standardization”. René Dirven et al. (eds.), Cognitive models in language and thought. Ideology, Metaphors and Meanings, Berlin / New York: Mouton de Gruyter, 2003: 25-68. Print.

Greig, J. Michael. "The end of geography? Globalization, communications, and culture in the international system". Journal of Conflict Resolution, 46 (2), (2002): 225-243. Web. 20 Apr. 2016.

Harris, Tracy K. "Judeo-Spanish: Survival and decline". Raphael Gatenio (ed.), JudeoEspaniol. The Evolution of a Culture, Thessaloniki: Ets Ahaim Foundation, 1999: 119-137. Print.

-. "The State of Ladino Today". European Judaism, 44 (1), (2011): 51-61. Web. 10 Feb. 2016.

Held, Michal. "The People Who Almost Forgot': Judeo-Spanish Web-Based Interactions as a Digital Home-Land". El Prezente: Studies in Sephardic Culture 4, (2010): 83102. Print.

Hetzer, Armin. "Sephardic". Thomas Stolz and Éva Ágnes Csató (eds), Minor languages of Europe: a series of lectures at the University of Bremen, April - July 200030 , Bochum: Brockmeyer, 2001: 143-158. Print.

Hohenhaus, Peter. "Standardization, language change, resistance and the question of linguistic threat: $18^{\text {th }}$-century English and present-day German". Andrew Linn and Nicola McLelland (eds.), Standardization: Studies from the Germanic languages, Amsterdam / Philadelphia: John Benjamins Publishing Company, 2002: 153-178. Print. 
-. "Elements of traditional and "reverse" purism in relation to computer-mediated communication". Nils Langer and Winifred V. Davies (eds.), Linguistic Purism in the Germanic Languages, Berlin: Walter de Gruyter, 2005: 204-220. Print.

Lakoff, George and Mark Johnson. Metaphors We Live By. Chicago / London: University of Chicago Press, 1980. Print.

Langer, Nils, and Winifred V. Davies. "An Introduction to linguistic purism". Nils Langer and Winifred V. Davies (eds.), Linguistic Purism in the Germanic Languages, Berlin: Walter de Gruyter, 2005: 1-17. Print.

López Fernández, Inés. "El judeoespañol en Internet: usuarios y recursos". Tonos Digital, 29 (II), 2015. Web. 20 Nov. 2017.

Milroy, James. "Language ideologies and the consequences of standardization". Journal of sociolinguistics, 5 (4), (2001): 530-555. Web. 15 Jun. 2017.

Milroy, James and Lesley Milroy. Authority in language: Investigating standard English (fourth edition). London, New York: Routledge, 2012 [1985]. Print.

Minervini, Laura. "El desarrollo histórico del judeoespañol». Revista Internacional de Lingüística Iberoamericana IV, 2 (8), (2006): 13-34. Impreso.

- "Los estudios del español sefardí (judeoespañol, ladino). Aportaciones, métodos y problemas actuales". Estudis Romànics, 35, (2013): 323-334. Web. 20 Abr. 2018.

Moseley, Christopher (ed.). Atlas de las lenguas del mundo en peligro (3ra edición). París: Ediciones UNESCO, 2010. Web. 20 Abr. 2018.

Nedović Pons, Neda. "Taktike intersubjektivnosti u rekonstrukciji etnojezičkog identiteta sefardske zajednice». Anali Filološkog fakulteta, XXVIII (II), (2016): 55-91. Štampano.

Neustupný, Jiři V. "Language purism as a type of language correction". Björn H. Jernudd and Michael J. Shapiro (eds.), The politics of language purism, Berlin / New York: Mouton de Gruyter, 1989: 211-223. Print.

Patton, Michael Quinn. Qualitative Evaluation and Research Methods (third edition). Thousand Oaks / London / New Delhi: SAGE Publications, 2002. Print.

Pierson, Benjamin Lee. ¿El último grito del ladino? El judeoespañol en el ciberespacio. M. A. thesis, unpublished manuscript. Fairfax, VA, USA: George Mason University, 2010. Web. 25 Apr. 2015.

Quintana, Aldina. "El judeoespañol, una lengua pluricéntrica al margen del español”. Paloma Díaz-Más y María Sánchez Pérez (eds.), Los sefardíes ante los retos del mundo contemporáneo. Identidad y mentalidades, Madrid: CSIC, 2010: 33-54. Impreso.

Robertson, Roland. Globalization: Social theory and global culture. London: SAGE Publications, 1992. Print.

Robertson, Roland. "Glocalization: Time-Space and Homogeneity-Heterogeneity". Mike Featherstone, Scott Lash and Roland Robertson (eds.), Global modernities, London: SAGE Publications, 1995: 25-44. Print. 
Romero, Elena. "La polémica sobre el judeoespañol en la prensa sefardí del imperio otomano: materiales para su estudio". Paloma Díaz-Más y María Sánchez Pérez (eds), Los sefardíes ante los retos del mundo contemporáneo. Identidad y mentalidades, Madrid: CSIC, 2010: 55-64. Impreso.

Romero, Rey. "Dialect concentration and dissipation: Challenges to Judeo-Spanish revitalization efforts". Bryan Kirschen (ed.), Judeo-Spanish and the Making of a Community, Cambridge Scholars Publishing, 2015: 50-71. Print.

- "En tierras virtualas: Sociolinguistic implications for Judeo-Spanish as a Cybervernacular". Mahir Şaul and José Ignacio Hualde (eds.), Sepharad as Imagined Community, New York / Bern / Frankfurt / Berlin / Brussels / Vienna / Oxford / Warsaw: Peter Lang, 2017: 275-290. Kindle Edition.

Roudometof, Victor. "Transnationalism, cosmopolitanism and glocalization". Current sociology, 53 (1), (2005): 113-135. Web. 23 Oct. 2014.

Schreier, Margit. "Qualitative content analysis". Uwe Flick (ed.), The SACE Handbook of Qualitative Data Analysis, Los Angeles / London / New Delhi, Singapore / Washington DC: SAGE Publications, 2014: 170-183. Print.

Schuerkens, Ulrike. "The sociological and anthropological study of globalization and localization". Current Sociology, 51 (3-4), (2003): 209-222. Web. 15 Sep. 2015.

Seloni, Lisya and Yusuf Sarfati. "(Trans)national language ideologies and family language practices: a life history inquiry of Judeo-Spanish in Turkey". Language Policy, 12 (1), (2013): 7-26. Web. 12 Feb. 2016.

Séphiha, Haim Vidal. “BIBLES JUDÉO-ESPAGNOLES: Ladino (judéo-espagnol calque) et Djudezmo (judéo-espagnol vernaculaire)". Revue Européenne des Études Hébraïques, 3, 35-56. Web. 15 Apr. 2015.

Shaul, Moshe. "Grafia del djudeo-espanyol al uzo de "Aki Yerushalayim"". Aki Yerushalayim 75, (2004). Web. 23 Feb. 2018.

Simons, Gary F. and Charles D. Fennig (eds). Ethnologue: Languages of the World, Twenty-first edition. Dallas, Texas: SIL International, 2018. Web. 22 Feb. 2018.

Spolsky, Bernard. Language policy. Cambridge: Cambridge University Press, 2004. Print.

-. Language management. New York: Cambridge University Press, 2009. Print.

Štulić, Ana and Soufiane Rouissi. "The Judeo-Spanish on the Web". Mahir Şaul and José Ignacio Hualde (eds.), Sepharad as Imagined Community, New York / Bern / Frankfurt / Berlin / Brussels / Vienna / Oxford / Warsaw: Peter Lang, 2017: 290_ 313. Kindle Edition.

Saul, Mahir. "What's in a name? Ladino, Espanyol, Djudyo, Judeoespañol, Sefardi". Mahir Saul (ed.), Judeo-Spanish in the Time of Clamoring Nationalisms, Istanbul: Libra, 2013: 179-253. Print.

Thomas, George. Linguistic purism. London / New York: Longman, 1991. Print.

Trask, Robert Lawrence. Language and linguistics: The key concepts (second edition), edited by Peter Stockwell. Oxon / NewYork: Routledge, 2007. Print.

UNESCO. Vitalidad y peligro de desaparición de las lenguas, Grupo especial de expertos 
sobre las lenguas en peligro convocado por la UNESCO. Paris: 2003. Web. 17 Abr. 2018.

Vidaković-Petrov, Krinka. Kultura španskih Jevreja na jugoslovenskom tlu. XVI-XX vek (3. dopunjeno izdanje). Beograd: Narodna knjiga, Alfa, 2001 [1986]. Štampano.

Vučina Simović, Ivana. "El léxico lingüícida vs. favorecedor en el proceso de mantenimiento desplazamiento del judeoespañol de Oriente". Winfried Busse y Michael Studemund-Halévy (eds.), Lexicología y lexicografía judeoespañolas, Bern: Peter Lang, 2011: 143-164. Impreso.

Vučina Simović, Ivana. Jevrejsko-španski jezik na Balkanu. Kragujevac: Filološko-umetnički fakultet, 2016. Štampano.

Vučina Simović, Ivana i Jelena Filipović. Etnički identitet i zamena jezika u sefardskoj zajednici u Beogradu. Beograd: Zavod za udžbenike, 2009. Štampano.

Zucker, George. K. "Ladino, Judezmo, Spanyolit, El Kasteyano Muestro". Shofar: An Interdisciplinary Journal of Jewish Studies, 19(4), (2001): 4-14. Web. 14 Oct. 2015.

Fecha de recepción: 15 de enero de 2018. Fecha de aceptación: 20 de abril de 2018. 